\title{
Behavior of concrete-filled double skin steel tubular columns under eccentric compression after fire
}

\author{
X. Liu ${ }^{a *}$, J. Y. Xu and B. Wang ${ }^{\mathrm{a}}$

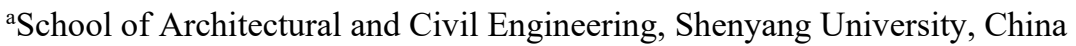 \\ *X.Liu, 489298344@qq.com
}

\begin{abstract}
:
To analysis the behavior of the mechanical properties of concrete-filled double skin steel tubular (CFDST) columns under eccentric loads after fire, the finite element analysis was used. The established FEA modeling was verified by the experimental results which has a good agreement. The FEA modeling was then used to perform the temperature field and the full-range load-deformation relations of the CFDST subject to eccentric compression after exposed to fire. The results indicate that: with the time of fire increasing, the eccentric distance increasing, the steel ratio decreasing, the yield strength decreasing and compressive strength decreasing, the bearing capacity of CFDST in circle section under eccentric loads is showing a decrease trend, and the stiffness of component decreases with the time of fire increasing, the eccentric distance increasing and the steel ratio decreasing. The ductility of CFDST became better with the time of fire increasing and the eccentric distance increasing.
\end{abstract}

Keywords: concrete-filled double skin steel tubular columns; eccentric compression; after exposed to fire; hollow ratio.

\section{Introduction}

Concrete-filled double skin steel tube (CFDST) columns has higher flexural rigidity, better plasticity and toughness, better seismic performance and better fire-resistant performance[1-4]. Recently, building fires occur frequently and that lead to massive personnel casualties and property damaged. With the good system of firefighting circumstance day by day, the steel can restore its most part bearing capacity after short fire, which is good to repair the construction. So it is significant to get the evaluation method of residual bearing capacity. Many researchers have carried out experiments on behavior of the CFDST about axial load, however CFDST always used in the constructions of high-rise buildings, ocean platform, and piers that most bear the eccentric compression.

The finite element analysis model was validated by a serious of experiments' data [5], which had a good agreement. Different parameters are selected in the research on the temperature field and full-range loaddeformation relations of the CFDST, which are fire exposure time, eccentric distance, hollow ratio, nominal steel ratio of CFDST, steel strength and concrete strength.

Table 1. Information of CFDST specimens

\begin{tabular}{ccccccccccccc}
\hline Specimen label & $\begin{array}{c}\boldsymbol{D}_{\mathbf{0}} \times \boldsymbol{t}_{\mathbf{0}} \\
(\mathbf{m m})\end{array}$ & $\begin{array}{c}\boldsymbol{D}_{\mathbf{i}} \times \boldsymbol{t}_{\mathbf{i}} \\
(\mathbf{m m})\end{array}$ & $\begin{array}{c}\boldsymbol{f}_{\mathbf{y} \mathbf{0}} \\
\mathbf{M P a})\end{array}$ & $\begin{array}{c}\boldsymbol{f}_{\mathbf{y i}} \\
\mathbf{( M P a})\end{array}$ & $\chi$ & $\boldsymbol{f}_{\mathbf{c u}}$ & $\begin{array}{c}\boldsymbol{L} \\
(\mathbf{m m})\end{array}$ & $\boldsymbol{\lambda}$ & $\boldsymbol{e}$ & $\begin{array}{c}\boldsymbol{N}_{\mathbf{u e}} \\
(\mathbf{K N})\end{array}$ & $\begin{array}{c}\boldsymbol{N}_{\mathbf{c}} \\
(\mathbf{K N})\end{array}$ & $\frac{N_{u e}}{N_{c}}$ \\
\hline Pcc1-1 & $114 \times 3$ & $58 \times 3$ & 294.5 & 374.5 & 0.54 & 46.8 & 887 & 28 & 4 & 638 & 635 & 0.995 \\
Pcc1-2 & $114 \times 3$ & $58 \times 3$ & 294.5 & 374.5 & 0.54 & 46.8 & 887 & 28 & 14 & 549 & 544 & 0.991 \\
Pcc1-3 & $114 \times 3$ & $58 \times 3$ & 294.5 & 374.5 & 0.54 & 46.8 & 887 & 28 & 45 & 312 & 319 & 1.022 \\
Pcc2-1 & $114 \times 3$ & $58 \times 3$ & 294.5 & 374.5 & 0.54 & 46.8 & 1770 & 56 & 0 & 620 & 612 & 0.987 \\
Pcc2-2 & $114 \times 3$ & $58 \times 3$ & 294.5 & 374.5 & 0.54 & 46.8 & 1770 & 56 & 15.5 & 400 & 404 & 1.010 \\
Pcc1-3 & $114 \times 3$ & $58 \times 3$ & 294.5 & 374.5 & 0.54 & 46.8 & 1770 & 56 & 45 & 228 & 251 & 1.101 \\
\hline
\end{tabular}

$\mathrm{N}_{\text {ue }}$ is Measured results, $\mathrm{N}_{\mathrm{c}}$ is calculated results. 


\section{Model validation}

\subsection{Test parameters}

Table 1 shows the details of test information.

\subsection{Material properties, mesh, boundary conditions, load method and interface properties}

Considering the temperature and confining to the sandwich concrete, Lin's damaged plasticity model was adopted [6]. The steel microstructure would change with the heat, shown that the strength of steel decreases with increasing temperature, but steel strength increase when temperature recovery to normal. Han's double broken line model considered this effect, so it was adopted in this CFDST member [7]. Eq. (1) shows the steel model after exposure fire.

$$
f_{y}\left(T_{\max }\right)= \begin{cases}f_{y} & T_{\max } \leq 400^{\circ} \mathrm{C} \\ f_{y}\left[1+2.23 \times 10^{-4}\left(T_{\max }-20\right)-5.88 \times 10^{-7}\left(T_{\max }-20\right)^{2}\right] & T_{\max }>400^{\circ} \mathrm{C}\end{cases}
$$

$f_{\mathrm{y}}\left(T_{\max }\right)$ is the yield strength after exposure to fire, $T_{\max }$ is maximum temperature during exposure to fire.

Steel tube is simulated by 4 node shell element(S4R), that adopt 9 Simpson integration point along the shell thickness to get accuracy. Concrete and end plates are simulated by 8 node brick element (C3D8R). By using structured grid partition technology, the unit grids are divided into each component [8].

The loading conditions were applied by using boundary conditions of each crosssection. The bottom end plate was fixed against all types displacements and top end plate was fixed against $\mathrm{X}$ and $\mathrm{Y}$ directions displacements. For rotations, both top and bottom end plates were fixed against $\mathrm{X}$ and $\mathrm{Z}$ directions. So the boundary conditions were hinge joint. The loading conditions and boundary conditions were applied by line on the end plates. End plates and fixture are regard as rigid body. 'Hard contact' was assigned for the normal behavior between end plate and concrete, which allows pressure exist when the surfaces contact, and no pressure will be transferred when the surfaces separate. In the interface contact, the Coulomb friction model was applied in the tangential direction and the hard-contact model was applied in the normal direction between outer and inner steel tube and concrete. Where the frictional factor $(\mu)$ was taken as 0.25[9]. Fig. 1 shows the mesh, boundary condition and details.

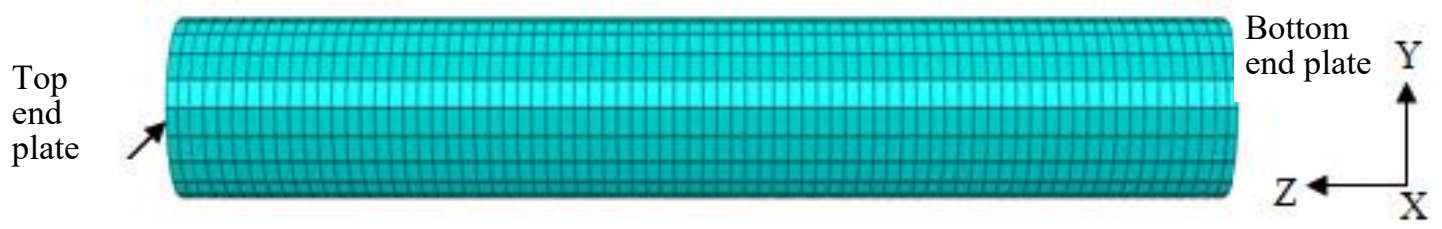

(a) Mesh

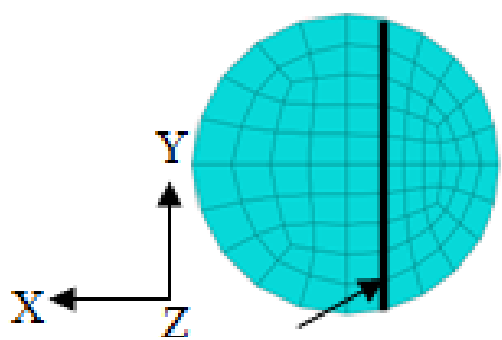

Eccentric load

Constrain X,Y displacement

(b) Top end plate and boundary condition

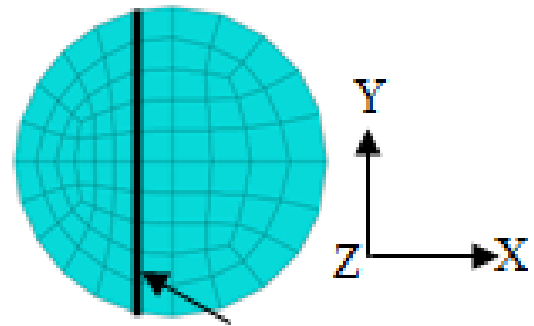

Eccentric load

Constrain X,Y, Z displacement

(c) Bottom end plate and boundary condition

Fig. 1. Mesh and boundary condition

\subsection{Verifications of the FEA model}

Table 1 shows the calculated results that were compared with test results, and the mean value of $\mathrm{N}_{\mathrm{ue}} / \mathrm{N}_{\mathrm{c}}$ is 1.108 , with coefficient of variation $(\mathrm{COV})$ of 0.0092 . Fig 2 shows load $(N)$-deformation $\left(u_{\mathrm{m}}\right)$ relation of experiment and calculated by FEA, which shows the good 
agreement. In general, the proposed FEA model was reasonable accuracy.

\section{Thermal analysis}

To get the temperature distribution under the ISO-834 standard fire condition, the thermal
FEA model was set up to simulate the fire. Both steel and concrete thermal properties were proposed by Lie [10]. Conduction, convection and radiation were three modes of heat transfer, and mainly considered in the CFDST were convection and radiation, ignoring the thermal

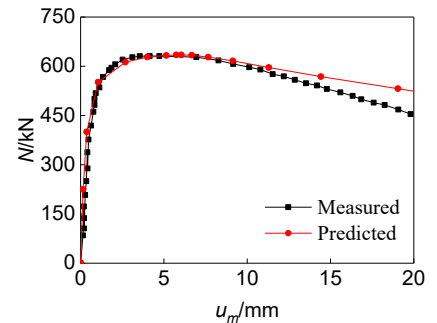

(a)Pcc1-1

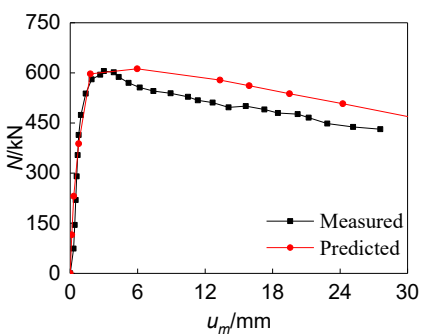

(d)Pcc2-1

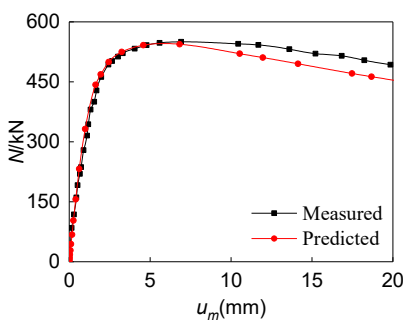

(b)Pcc1-2

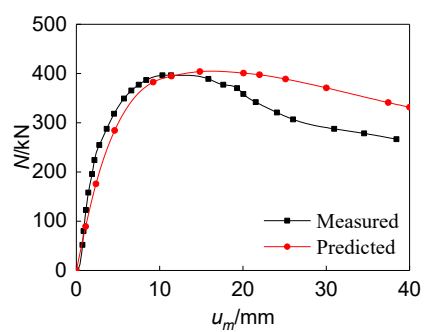

(e)Pcc2-2

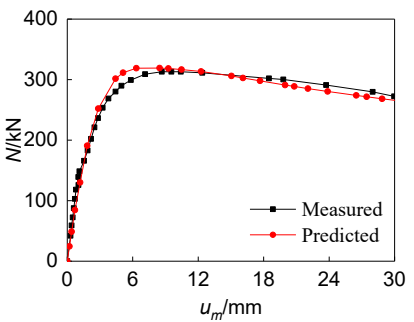

(c)Pcc1-3

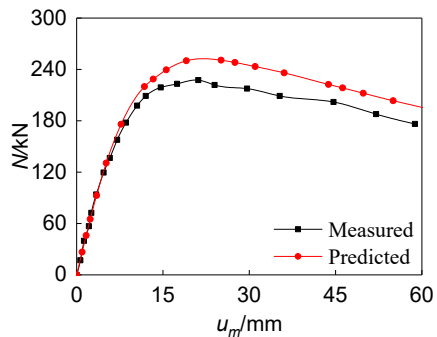

(f)Pcc2-3

Fig. 2. $\mathrm{N}-\mathrm{u}_{\mathrm{m}}$ relations of CFDST
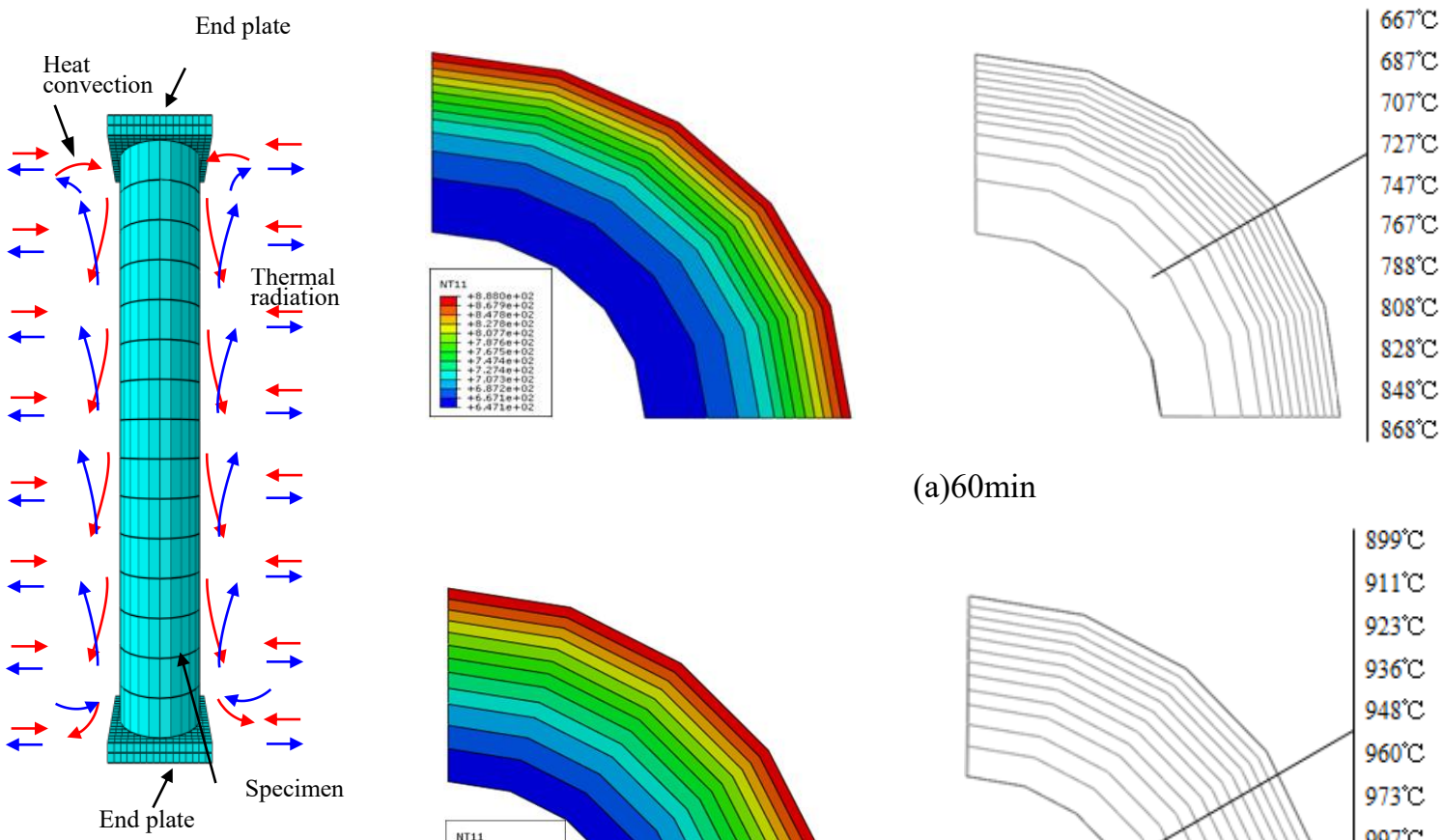

(a)60min

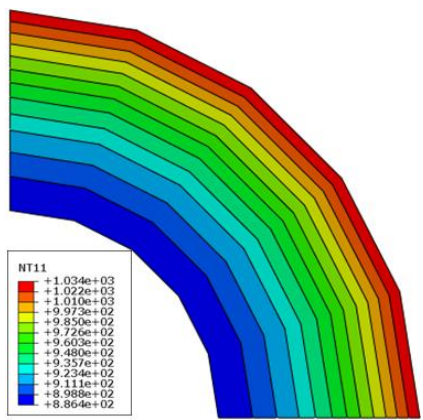

Fig. 3. Mesh and heat

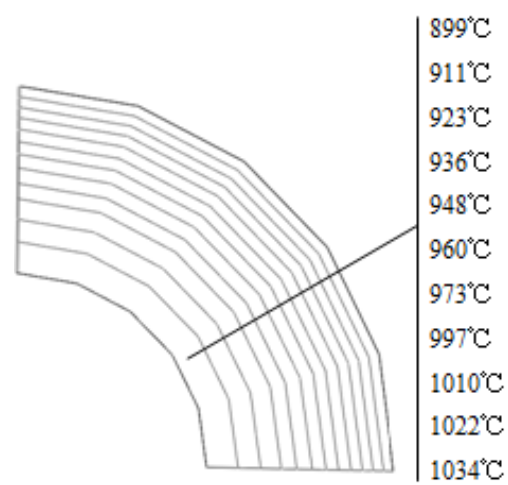

(b)120min 
analysis boundary condition

resistance between concrete and steel tube. 'Tie' was assigned in the interface between outer, inner steel tube and concrete. Outer and inner steel tube was simulated by 4 node heat transfer quadrilateral shell (DS4) and concrete was simulated by 8 node liner heat transfer brick(DC3D8). Fig.3 shows mesh and boundary condition.

Fig.4 shows distribution of temperature in the section of mid-span. Hollow ratio $(\chi)$ is 0.54 and heating time $(t)$ is 60 minutes and 120 minutes, respectively. It can be found that the distribution of isotherm is a series concentric circles. Temperature decrease from outside to inside, and the temperature gradient in outer steel tube is large. The temperature gradient inner steel tube is slow in $t=60 \mathrm{~min}$, but large with the heat raising which shown in $t=120 \mathrm{~min}$. When heating time is 60 minutes, temperature variance is 201 degrees Celsius between inner and outer steel tube, while it turns to 135 degrees Celsius when heating time is 120 minutes. Concrete absorb quantity heat that protect inner steel tube heat up slowly when member was exposed to fire. So CFDST has good fire resistance and better load bearing capacity and ductility after exposure to fire.

\section{Parameters analytical}

Based on the correct FEA model to analyze the full-range load-deformation relations of the CFDST subjected to eccentric compression. The parameters are as follows: heating time $t$ (0min, 60min and 90min), eccentric distance e (4mm, $14 \mathrm{~mm}$ and $45 \mathrm{~mm})$, nominal steel ratio an $(0.075,0.114$, and 0.157$)$, outer steel yield strength $f_{\text {yo }} \quad(294.5 \mathrm{MPa}, \quad 374.5 \mathrm{MPa}$ and
Fig. 4. Cross section temperature

$500 \mathrm{MPa})$, and compressive strength of concrete $f_{\text {cu }}(46.8 \mathrm{MPa}, 68 \mathrm{MPa}$ and $88 \mathrm{MPa})$.

Fig.5 shows different heating time in the load-deformation relations $\left(N-u_{\mathrm{m}}\right)$. It can be found that load bearing capacity $(N)$ will decrease with heating time $(t)$ increase. Compared to the normal temperature, the load bearing capacity decreased $30.12 \%$ when $t=60 \mathrm{~min}$ as well as $39.35 \%$ when $\mathrm{t}=120 \mathrm{~min}$. The different between them was merely $9.35 \%$, which shown the bearing capacity decreased faster in $60 \mathrm{~min}$ but slower in more. With heating time $(t)$ increased, the elastic stage shorten and the stiffness of elastic-plastic stage decreased. But the descending stage flattens out and ductility became better. The reason is that crack cut through concrete which make mechanical property degrade severely and will not recover after exposure to fire, and it will be worse with heating time increase. However mechanical property and strength of steel will be recovered when cooling to normal temperature. So the "contribution" of the sandwich concrete and steel on the bearing capacity of the CFDST has changed. The concrete bearing capacity loss seriously and the steel bears the mainly load after exposure to fire. When $t=60 \mathrm{~min}$, the bearing capacity decrease severely compared with ambient temperature condition. In can be found in Fig.4(a) that the temperature of concrete near inner tube is about $6677^{\circ} \mathrm{C}$, while that will be about $900{ }^{\circ} \mathrm{C}$ when $\mathrm{t}=120 \mathrm{~min}$. However the strength of concrete reduces $70 \%$ at $700{ }^{\circ} \mathrm{C}$, at that time concrete's "contribution" is little to the CFDST and steel plays a leading role. So there are little difference between 60 minutes and 120 minutes.

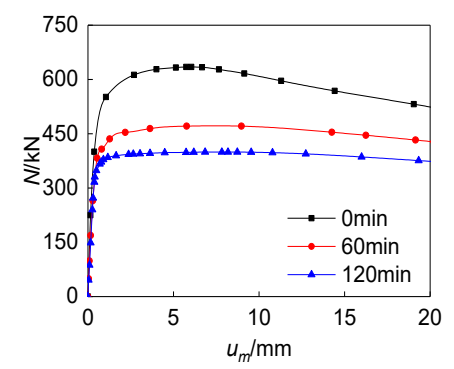

(a) $e=4 \mathrm{~mm}$

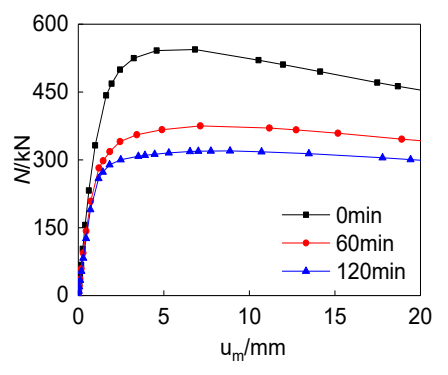

(b) $e=14 \mathrm{~mm}$

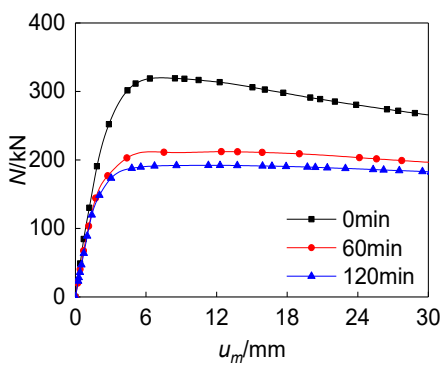

(c) $e=45 \mathrm{~mm}$

Fig. 5. $\mathrm{N}-u_{m}$ relations of CFDST after exposed to fire 
Fig.6 shows load bearing capacity versus deformation curve $\left(N-u_{\mathrm{m}}\right)$ respect to eccentric distance in mid-span. In ambient temperature condition, bearing capacity fells at a rate of $14.29 \%$ and $49.71 \%$ respectively with eccentric distance increasing. When heating time is 60 minutes, bearing capacity fells at a rate of $20.41 \%$ and $55.00 \%$ respectively with eccentric distance increasing. When heating time is 120 minutes, bearing capacity fells at a rate of
$19.94 \%$ and $51.88 \%$ respectively with eccentric distance increasing. It shows that load bearing capacity decrease with eccentric distance increase and heating time have little influence on its range. Stiffness decrease with eccentric distance increase and the mid-span deflection increase with eccentric distance increasing. After the ultimate load the curve decline slowly and the ductility will be better with eccentric distance increase.

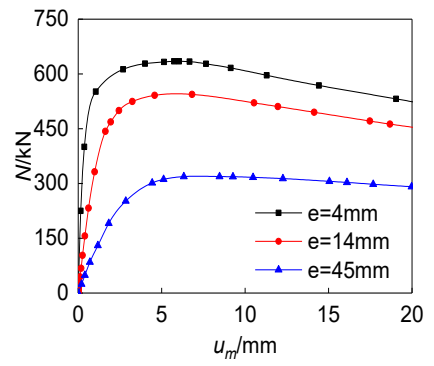

(a) $t=0 \mathrm{~min}$

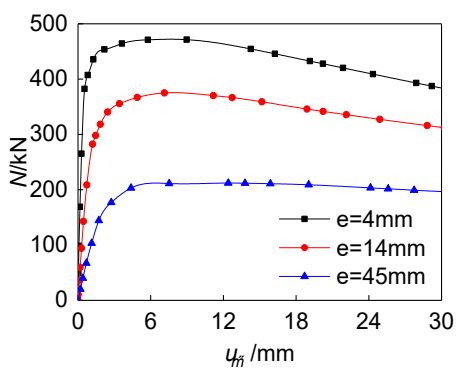

(b) $t=60 \mathrm{~min}$

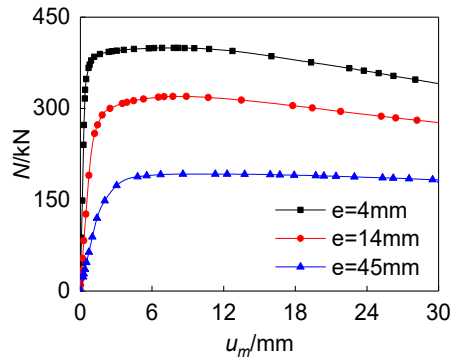

(c) $t=120 \mathrm{~min}$

Fig. 6. $\mathrm{N}-u_{m}$ relations of CFDST respect to different eccentric distance

Fig.7 shows peak load versus nominal steel ratio histogram respect to different heating time and eccentric distance. It can be seen that load bearing capacity increase with nominal steel ratio increase. The increasing percentage is $7.18 \%$ and $36.98 \%$ respectively in ambient temperature condition, $17.46 \%$ and $42.71 \%$ respectively when heating time is 60 minutes, and $25.99 \%$ and $53.05 \%$ respectively when heating time is 120 minutes. With heating time and nominal ration of steel increasing, the percentage of load bearing capacity increase,

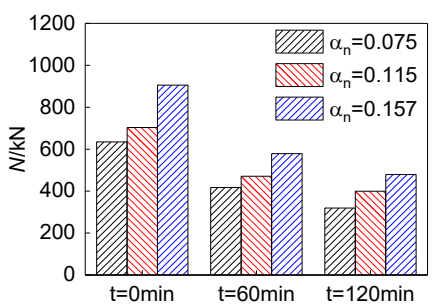

(a) $e=4 \mathrm{~mm}$

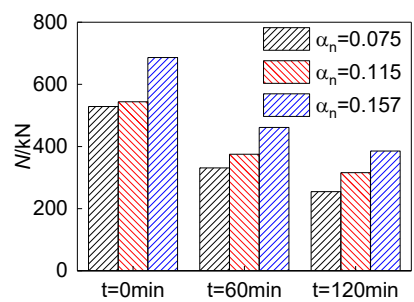

(b) $e=14 \mathrm{~mm}$

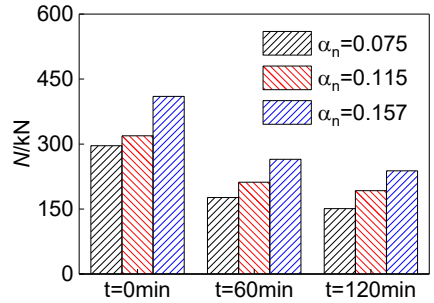

(c) $e=45 \mathrm{~mm}$

Fig. 7. Load capacity $(N)$ respect to different steel ratio $\left(\alpha_{n}\right)$ 


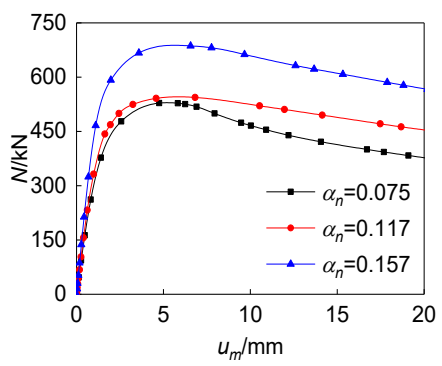

(a) $t=0 \mathrm{~min}$

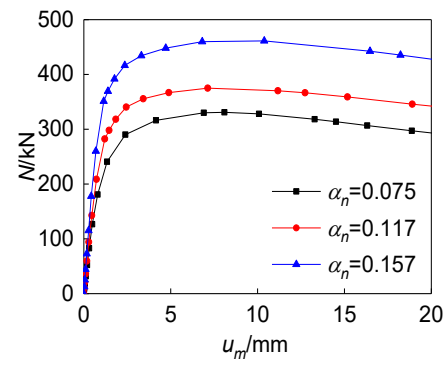

(b) $t=60 \mathrm{~min}$

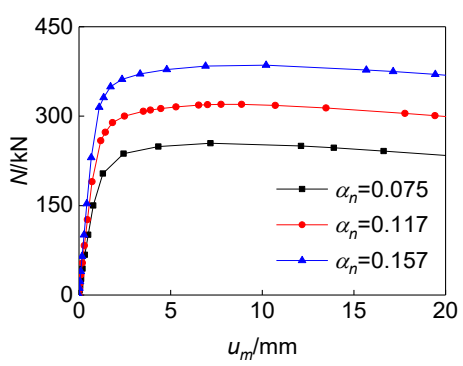

(c) $t=120 \mathrm{~min}$

Fig. 8. $N-u_{m}$ relations of CFDST respect to different steel ratio

Fig.9 shows load bearing capacity versus deformation $\left(N-u_{\mathrm{m}}\right)$ relation respect to different yield strength of outer steel tube $\left(f_{\mathrm{yo}}\right)$. Stiffness is almost not been effected by yield strength of outer steel tube in elastic stage but increase in elastic-plastic stage with yield strength of outer steel tube increase and deformation increase slightly in mid-span. Constraint effect became better with $f_{\text {yo }}$ increase, which results in load bearing capacity higher, but $f_{y o}$ has little effect on ductility.

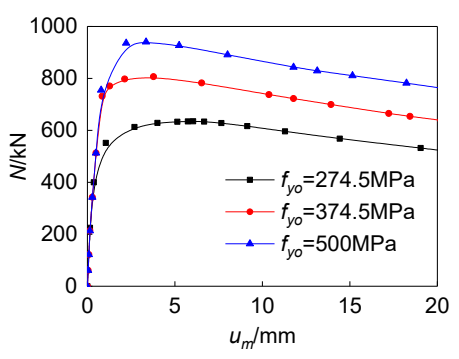

(a) $t=0 \mathrm{~min}$

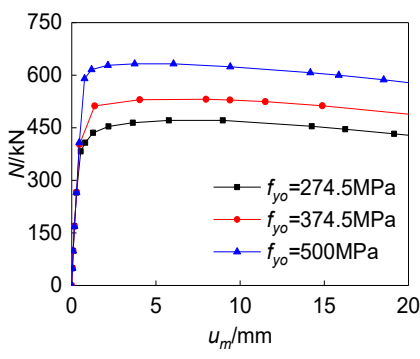

(b) $t=60 \mathrm{~min}$

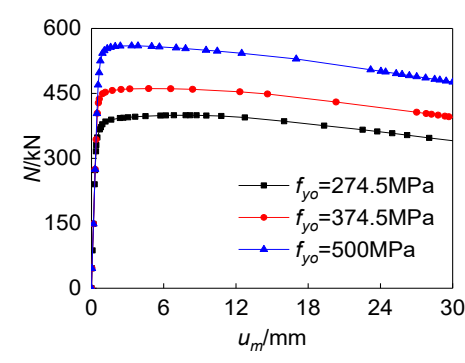

(c) $t=120 \mathrm{~min}$

Fig. 9. $N-u_{m}$ relations respect to different yield strength of outer tube

Fig.10 shows load bearing capacity versus deformation $\left(N-u_{\mathrm{m}}\right)$ relation respect to different compressive strength of concrete $\left(f_{\text {cu }}\right)$. Load bearing capacity $(N)$ and stiffness both increase with $f_{c u}$ increase, but the amplitude of increase is less and less stark. When $t$ is less than $60 \mathrm{~min}$, the descending stage is more and more obvious with compressive strength of concrete $\left(f_{\text {cu }}\right)$ increase. Because constraint effect provided by steel tube will be worse which result in ductility worse. When $\mathrm{t}$ more than $60 \mathrm{~min}$, descending stage declined very slowly.

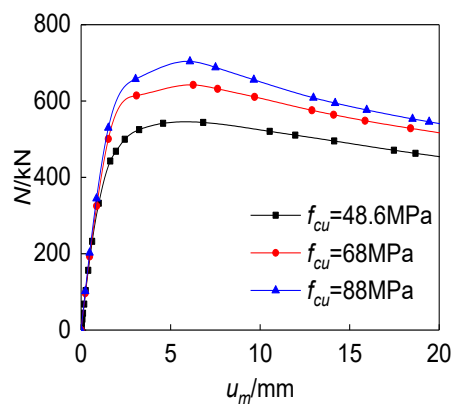

(a) $t=0 \mathrm{~min}$

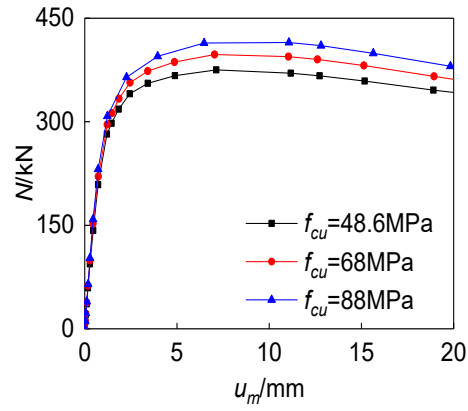

(b) $t=60 \mathrm{~min}$

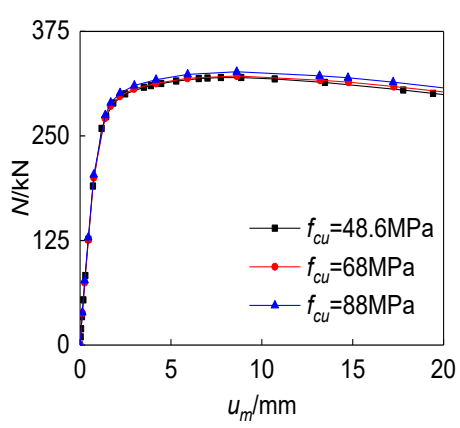

(c) $t=120 \mathrm{~min}$

Fig. 10. $N-u_{m}$ relations respect to different concrete strength $(e=14 \mathrm{~mm})$

In Fig.11, the parameters of CFDST are: $f_{\mathrm{cu}}=46.8 \mathrm{MPa}, f_{\mathrm{yo}}=374.5 \mathrm{MPa}, f_{\mathrm{yi}}=294.5 \mathrm{MPa}$, $D_{\mathrm{o}}=114 \mathrm{~mm}, \quad D_{\mathrm{i}}=58 \mathrm{~mm}, \quad t_{0}=3 \mathrm{~mm}, \quad t_{\mathrm{i}}=3 \mathrm{~mm}$, $L=887 \mathrm{~mm}, e=14 \mathrm{~mm}, t=60 \mathrm{~min}$.
Fig.11(a) shows the typical load bearing capacity versus deformation relation $\left(N-u_{\mathrm{m}}\right)$ in mid-span of CFDST under eccentric load after exposure to fire. Four feature points in the fullrange which divide the curve into three stages 
where $\mathrm{O}$ is the start point of eccentric load, $\mathrm{A}$ is the point of the end of elastic stage, $\mathrm{B}$ is the peak point and $\mathrm{C}$ is the point of the deformation $u_{\mathrm{m}}=20 \mathrm{~mm}$ :

Stage1: Elastic stage (from O to A). During this stage, pressure stress increase from point $\mathrm{O}$ to point $\mathrm{A}$, and there are no tensile stress in mid-span section. The stress increase from far side of eccentric load action to near side as shown in Fig.11 (b).

Stage2: Elastic-plastic stage (from A to B). During this stage, with the increasing of eccentric load, tensile stress comes up at the far side, so one side is tensile stress and another side is pressure stress and the range of tensile stress gradually larger. But the stress of outer and inner steel tube don't reach the yield strength. So inner steel tube, concrete and outer steel tube work together well and confinement

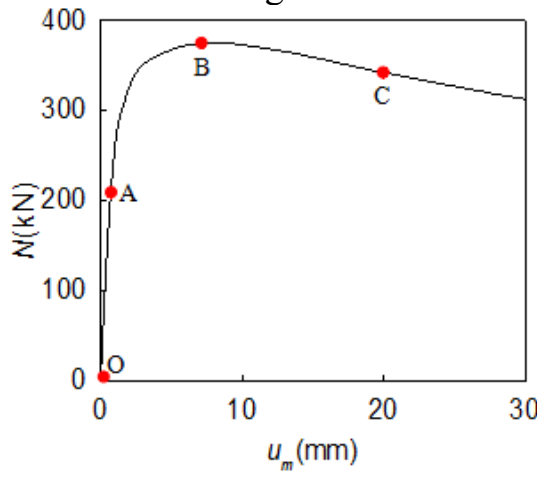

(a) Typical $N$ - $u_{m}$ curve

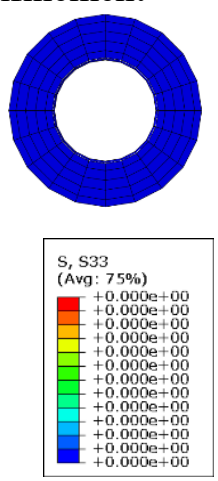

(b) point 0

effect results in load capacity increasing until point B as shown in Fig.11 (c).

Stage3: Descending stage BC (from B to C). During this stage, the stress of inner and outer steel tube exceed yield strength and occur in mid-span section first. The tensile area of concrete get larger and the stress of inner tube change from all pressure to far side in tension and near side in pressure of loading line. Under eccentric load, outward local buckling occur in outer steel tube and inward buckling occur in inner steel tube. Concrete has already broken and there are some cracks cutting through concrete in tension area. Inner and outer steel tube has already separate from concrete. Deformation in mid-span section increase rapidly while load bearing capacity decrease a lot as shown in Fig.11 (e).
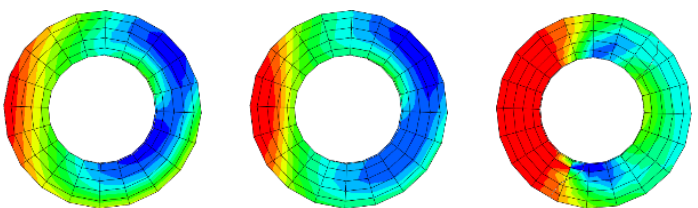

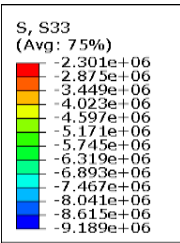

(c) point $\mathrm{A}$

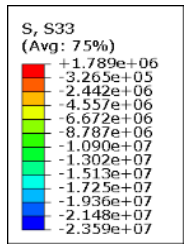

(d) point $B$

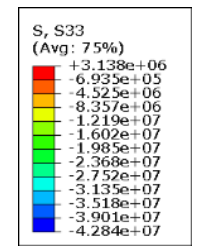

(e) point $\mathrm{C}$

Fig. 11. Typical $N-u_{m}$ curve and longitudinal stress distribution of mid-span

\section{Conclusions}

(1)The eccentric compression load versus longitudinal displacement curves in mid-span calculated by finite element method in this paper show good agreement with test results.

(2)With heating time and eccentric distance increase, bearing capicity of CFDST after exposure to fire will decrease. With nominal steel ratio of CFDST, yield strength of outer steel tube and compressive strength of concrete increase, bearing capicity of CFDST after exposure to fire will increase.

(3)Typical $N-u_{\mathrm{m}}$ curve in mid-span included three stage: elastic stage, elasticplastic stage and descending stage.

\section{References}

[1] Tao Z, Han LH, Zhao XL. Behavior of concretefilled double skin (CHS inner and CHS outer) steel tubular stub columns and beam-columns. Journal of Constructional Steel Research. 2004; 60(8):1129-58.

[2] Liu X, Li M, Wang L. Full-range analysis of steel columns filled with steel-reinforced concrete subjected to compression-flexure loading [J]. Journal of Harbin institute of technology, 2012; 44(6): 121-125. (in Chinese)

[3] Yang YF, Han LH. Fire resistance of concretefilled double skin steel tubular columns. Fourth International Conference on Advances in Steel Structures. Oxford: Elsevier Science Ltd; 2005; 10(5):47-52.

[4] Huang H, Han LH, Tao Z, Zhao XL. Analytical behavior of concrete-filled double skin steel tubular (CFDST) stub columns. Journal of 
Constructional Steel Research. 2010; 66(4):54255.

[5] Li W, Guo Z. Experimental study on strength and deformation of concrete at high temperature [J]. 1993; 14(1):8-16.

[6] Lin X. Cyclic performance of concrete-filled steel tubular columns after exposure to fire [D]. Fuzhou: Fuzhou University, 2006. (in Chinese)

[7] Han LH, Huang H, Zhao XL. Analytical behaviour of concrete-filled double skin steel tubular (CFDST) beam-columns under cyclic loading. Thin-Walled Structures. 2009; 47(6):668-80.

[8] Huang H, Han LH, Zhao XL. Investigation on concrete-filled double skin steel tubes (CFDSTs) under pure torsion. Journal of Constructional Steel Research. 2013; 90: 221-34.

[9] Liu W. Research on mechanism of concretefilled steel tubes subjected to local compression [D]. Fuzhou: Fuzhou University, 2006. (in Chinese)

[10]Lie, TT. Fire resistance of circular steel columns filled with bar-reinforced concrete. Journal of Structural Engineering, 1994; 120(5):1489-1509. 